\title{
Homonymous Visual Field Defect
}

National Cancer Institute

\section{Source}

National Cancer Institute. Homonymous Visual Field Defect. NCI Thesaurus. Code

C118733.

A bilateral visual field defect on the same side of visual space of each eye (right or left). 